\title{
Active Thermal Method Applied to the In Situ Characterization of Insulating Materials in a Wall
}

\author{
Elorn Biteau $\left(\mathbb{D}\right.$, Didier Defer * ${ }^{\mathbb{D}}$, Franck Brachelet and Laurent Zalewski \\ University Artois, University Lille, Institut Mines-Télécom, Junia, ULR 4515-LGCgE, Laboratoire de Génie Civil \\ et géo-Environnement, F-62400 Béthune, France; elorn.biteau@univ-artois.fr (E.B.); \\ franck.brachelet@univ-artois.fr (F.B.); laurent.zalewski@univ-artois.fr (L.Z.) \\ * Correspondence: didier.defer@univ-artois.fr
}

check for

updates

Citation: Biteau, E.; Defer, D.; Brachelet, F.; Zalewski, L. Active Thermal Method Applied to the In Situ Characterization of Insulating Materials in a Wall. Buildings 2021, 11, 578. https://doi.org/10.3390/ buildings 11120578

\section{Academic Editors: Luís}

Filipe Almeida Bernardo and Miguel Nepomuceno

Received: 22 October 2021 Accepted: 22 November 2021 Published: 24 November 2021

Publisher's Note: MDPI stays neutral with regard to jurisdictional claims in published maps and institutional affiliations.

Copyright: (C) 2021 by the authors Licensee MDPI, Basel, Switzerland. This article is an open access article distributed under the terms and conditions of the Creative Commons Attribution (CC BY) license (https:/ / creativecommons.org/licenses/by/ $4.0 /)$.

\begin{abstract}
An in situ estimation of the thermal properties of bio-sourced building wall insulation components is of critical importance in improving both the energy efficiency of buildings and the development of construction materials with a smaller environmental footprint. Depending on weather conditions, passive methods are not always feasible; they require time to conduct lengthy testing and may lead to significant uncertainties. This article presents an active method based on power dissipation via flat electrical resistance. The method can be implemented regardless of outdoor weather conditions and is suitable for walls with high overall thermal resistance for which the small average component of the through flow is difficult to estimate. Measurements are conducted of both wall input flows and temperatures. An inverse method, derived from a finite difference model of 1D transfers along with a multi-objective approach, enables the characteristics of a two-material assembly to be identified. A multi-objective method was chosen to solve the problems of high correlation between the thermal parameters of the model. However, the method requires the use of two temperature sensors integrated inside the wall. Following a laboratory validation phase on a $\mathrm{PVC} /$ plasterboard assembly, the method is implemented on an actual wall. A coating/hemp concrete assembly is also characterized as part of this work program. The thermal conductivity of the hemp concrete block was estimated at $0.12 \mathrm{~W} \mathrm{~m}^{-1} \mathrm{~K}^{-1}$ and is consistent with values found in the literature.
\end{abstract}

Keywords: thermal conductivity; inverse method; multi-objective; in situ measurement; active method; hemp concrete

\section{Introduction}

With respect to the objectives of reducing the world's greenhouse gas emissions, the building sector offers the greatest source of potential actions, given its status as the largest final energy consumer [1]. Featuring an attractive carbon footprint, natural materials have become more popular during construction or renovation projects, whether the intention is to improve the insulating capacity of the wall or serve as a substitution for conventional load-bearing materials. Poor knowledge of the in situ thermal behavior of construction materials, in addition to discrepancies observed in their thermal properties relative to values determined in the laboratory [2-4], can prove detrimental to the objectives of a reduced energy consumption and a large-scale application of these materials. Along these lines, Majcen et al. [5] showed that small variations in the heat transfer coefficient may exert a major impact on residential energy consumption. The envelope performance gap is one of the causes of the performance gap between the design consumption and the observed consumption [6]. It becomes even more commonplace with older and less energy-efficient buildings. Inspired by Majcen et al., Menezes et al. [3] ascribed the effects of settlement, aging and water content in materials as sources of reduced envelope performance. The hygrothermal behavior of insulating materials has only been marginally studied when assessing the quantity of articles dealing with this topic. The works conducted to date on the thermal properties of insulating materials however do confirm a strong correlation between 
the rise in relative humidity in materials and their increased thermal conductivity $[7,8]$. The need therefore currently exists to enable monitoring the actual performance of insulating materials, over the course of seasons. The many projects underway in France targeting envelope performance monitoring (REHAFUTUR [9], ISABELE [10], RESBATI [11]), as is the case in other countries $[12,13]$, reveal the societal importance behind this focus on the in situ thermal behavior of building envelopes. The attention paid to bio-sourced materials in the construction industry has grown over the past few decades, as their use has become more widespread across the globe [14]. However, since their thermal behavior and thermal properties remain relatively unknown, considerable research has been dedicated to such materials, as reflected in the literature [15-18].

The in situ methods currently employed to characterize thermal properties mainly seek to determine the envelope's overall thermal resistance or heat transfer coefficient. These methods rely on both a temperature difference measurement and a heat flow that enables identifying thermal conductivity. Several studies have listed and compared these techniques [19,20], with the most widely used consisting of the heat flow meter method [21]. These processes are based on a passive study of the walls; they require observation periods in excess of 3 days and on occasion extend up to 2 weeks. Such methods are intended to study the weakly variable components of the heat transfer as it crosses the wall. Several conditions must be in place in order to yield an accurate estimation of the wall's resistance. Following the conditions of application described in ISO 9869 [22], the total uncertainty associated with the result can vary between $14 \%$ and $28 \%$. The work of Teni et al. [23] lists the uncertainties associated with the HFM method by different authors and shows very wide uncertainty ranges. A successful method application depends, in particular, on environmental conditions. It is necessary to observe adequately large deviations in average temperature between the inside and outside wall surfaces, which typically means encompassing periods that remain cold over several days. This constraint limits the periods when passive methods can be implemented. For walls with heavy thermal insulation, the observed heat flows diminish considerably, and the estimation of weakly or moderately variable components is associated with a high level of uncertainty, thus in turn affecting the wall strength estimation. It thus becomes difficult to study wall performance using a passive approach.

So-called active methods were thus developed for the purpose of evaluating the thermal performance of materials and walls by means of reducing the length of the observation period. These methods rely on an artificial thermal loading of the interior walls or volumes. One of the most regularly employed heating methods consists of imposing radiation, in a manner as uniform as possible, on the inside wall surface using halogen lamps. Temperatures on both sides of the walls are typically read with thermocouples, although the quantitative application of infrared thermal cameras has become increasingly widespread [24,25]. Contactless and non-intrusive, these methods offer the double advantage of minimizing disturbances of the observed thermal exchanges taking place at the wall surface and enabling a comprehensive wall approach. However, the observed heat transfers are indeed complex to analyze. The reflection phenomena and poor knowledge of both surface radiation characteristics [26] and ambient radiative temperature do introduce uncertainties into the surface temperature extraction step based on the radiometric equation.

Thermal properties can be determined by relying on inversion methods, built around a 1D model of the conductive exchanges taking place through the wall. The quadrupole method $[27,28]$ is especially well adapted to simple geometries. This method relies on an analysis within the Laplace space or on the temperature and flow evolution frequencies and moreover serves to determine the wall's total thermal capacities and conductance. Previous studies have also indicated the difficulties inherent in determining the thermal properties of heavy walls, owing to both the high thermal capacity of materials and the large time constants associated with the heat transfer phenomena in this category of wall [29].

The study herein is intended to propose an active method that enables an in situ estimation of the thermal properties for the heat transfer and storage of a material present 
in a multilayer wall. The primary objective consists of implementing this method for the purpose of characterizing insulating materials, with an emphasis on those that are biosourced or stem from a recycling process, both of which are currently quite popular. The approach entails applying a thermal load over a short duration with an electrical heating element in contact with the wall. A flat heating resistance of approx. $1 \mathrm{~m}^{2}$ has been used for application on an actual building in order to guarantee a unidirectional transfer within the instrumented central zone. This characterization device can be used independently of weather conditions. An inverse method has been developed to identify the thermal characteristics of materials by means of recording the inflow into the wall as well as temperatures at both the surface and interfaces. The article will proceed by introducing the principle behind this method and detailing the relevant theoretical developments using an experimental set-up produced in the laboratory. Next, the method is implemented on a wall of an occupied building that has undergone renovation and insulation works involving various bio-sourced materials. An insulated wall featuring a layer of hemp concrete is also studied as part of this work program.

\section{Method Development}

\subsection{Laboratory-Based Experimental Set-Up and Testing Protocol}

Figure 1 diagrams the experimental set-up studied in the laboratory. For the sake of clarity in this depiction, the various dimensions have not been drawn to scale.

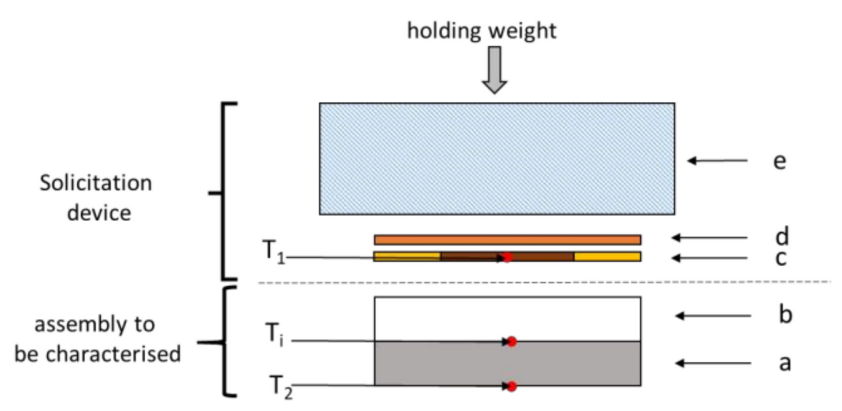

Figure 1. Experimental set-up.

An assembly was produced by simply placing two materials in contact; this assembly reflects the insulated side of a wall. The thermal characteristics known for both materials were close to those targeted in situ for the construction materials.

This assembly associated:

(a) a PVC-U Trovidur ${ }^{\circledR}$ plate with a surface area of $25 \times 25 \mathrm{~cm}^{2}$ and thickness of $1 \mathrm{~cm}$.

(b) plasterboard with a surface area of $25 \times 25 \mathrm{~cm}^{2}$ and thickness of $1.25 \mathrm{~cm}$. The assembly was used to position the loading and measurement device; it contained three elements.

(c) a heat flow meter with a surface area of $25 \times 25 \mathrm{~cm}^{2}$ and thickness of $0.5 \mathrm{~mm}$. This model of meter, Captec ${ }^{\circledR}$, is of the tangential gradient type and offers the advantage of being very thin $(500 \mu \mathrm{m})$ with a negligible thermal resistance in our specific case. The sensitive zone spans a surface area of $15 \times 15 \mathrm{~cm}^{2}$. An inert guard ring, of the same composition as the sensitive part, serves to guarantee the unidirectional aspect of exchanges taking place in the central part. In addition, a 2D model was carried out but is not presented in this work. It showed that under the test conditions the transfer regime was unidirectional in the measurement area.

(d) a flat heating resistance with a surface area of $25 \times 25 \mathrm{~cm}^{2}$ and resistance of $20.3 \Omega$ ensures a uniformly-distributed dissipation on the heating surface.

(e) a rigid, 6-cm thick polystyrene plate is positioned against the heating element in order to ensure that the majority of the power dissipated by the heating element is being directed toward the targeted two-layer complex. This plate also generates supporting 
pressure on the heating resistance surface area, while guaranteeing well distributed and constant contact conditions across the study surface area.

The heat flow meter sensitivity was measured according to the zero-flow method [30]; a heat flow density sensitivity of $116 \mu \mathrm{V} \mathrm{m}^{2} \mathrm{~W}^{-1}$ was obtained. Type $\mathrm{T}$ thermocouples were positioned as defined by the diagram description in Figure 1. A thermocouple was embedded into the flow meter and served to measure temperature $T_{1}(t)$ at the system input. Another was placed at the interface between the two assembly materials (temperature $\mathrm{T}_{\text {int }}(\mathrm{t})$ ), and a final one was installed in the back of the PVC plate (output temperature $\mathrm{T}_{2}(\mathrm{t})$ ). The thermocouples and flow meter were connected to a Graphtec ${ }^{\circledR}$ GL820 data logger. A calibration phase for the acquisition chain (thermocouple + data logger) made it possible to estimate the temperature measurement uncertainty at $\pm 0.3^{\circ} \mathrm{C}$. The uncertainty in the measurement of the flux density is estimated at $3 \%$. The flat heating resistance was connected to a Rigol ${ }^{\circledR}$ brand continuous voltage power supply. In this study, the power supply was set up to be activated manually in on-off mode.

Thermal characteristics were determined by means of an iterative inversion procedure. The inversion algorithm was based on a direct finite-difference numerical model, derived from a discretization of the second-order heat equation. To build a spatiotemporal model of the temperature field evolution in the materials, it was necessary to construct a hypothesis relative to the initial temperature field conditions. A layer of insulating material several centimetres thick holds the heating element to the wall. It reduces the heat transfer before the test and helps to reduce errors in the initial conditions. This device was installed several hours prior to running the test and turning on the heat so as to decrease heat transfers within the assembly. Under these conditions, upon launching the test, a steady-state regime hypothesis could be adopted to impose the initial temperature. Moreover, the electrical power feeding the heating resistance was only activated $20 \mathrm{~min}$ after starting the test to improve model initialization. A temperature $\left(\mathrm{T}_{1}(\mathrm{t}), \mathrm{T}_{\text {int }}(\mathrm{t}), \mathrm{T}_{2}(\mathrm{t})\right)$ and heat flux density $(\phi(t))$ data acquisition step was performed using a $10 \mathrm{~s}$ time step. Test duration was not optimized in this study, and acquisition was halted about three hours after the electrical power supply had been shut off as the system was gradually returning to a state of equilibrium.

For the test presented herein, two power supply pulses were imposed for the electrical resistance at the two-layer complex. The first lasted $30 \mathrm{~min}$ and was of a $200 \mathrm{Wm}^{-2}$ intensity, and the second, applied $30 \mathrm{~min}$ later, lasted an hour at the same intensity. These two pulses, spanning different intervals, yielded a thermal signal with a wide frequency spectrum while limiting the heat flow power. Since the method developed was intended for in situ application, the imposed heat flow power needed to strike a compromise. For one thing, it had to allow observation of temperature and flow signals with significant amplitudes compared to the measurement noise, and for another, it had to avoid causing coupled heat-mass transfers that can occur in wet materials due to excessive temperature gradients. The benefit of using power pulses generated during the tests held lies in the simplicity of signal implementation, which does not necessitate any additional equipment to manage loads of different shapes.

On the basis of this test, the inversion consists of seeking the combination of parameters that will best adjust the simulated interface flow and temperature signals on the corresponding experimental signals by imposing the temperatures of both the flow meter and back face of the PVC sample as system boundary conditions. The resulting system can thus be depicted by the equivalent diagram (Figure 2). 


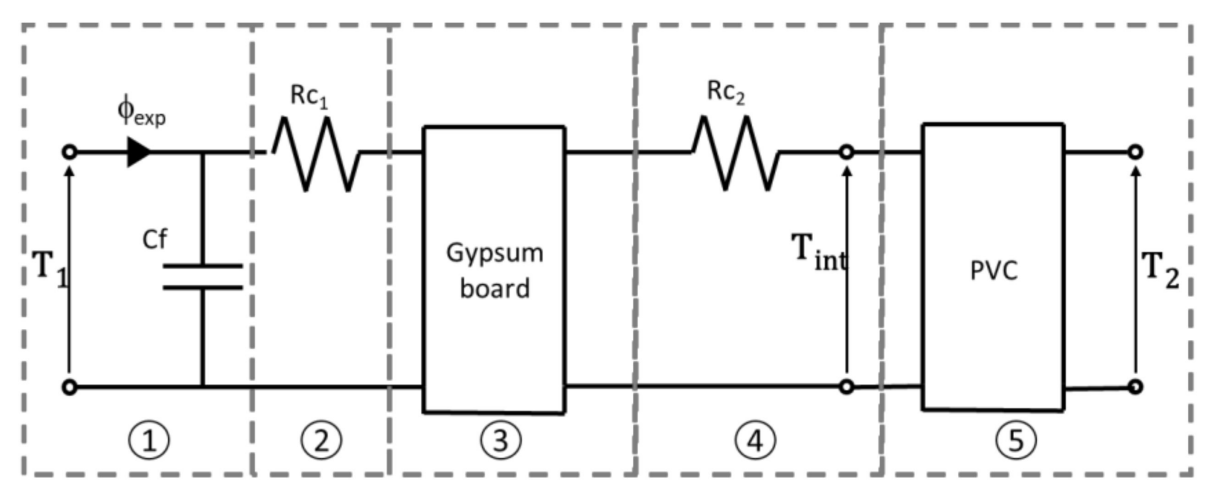

Figure 2. Equivalent diagram of the system under study.

This system can be considered as a series of five elements, namely:

1. Tangential gradient heat flow meter: Thanks to its thickness and type of component materials, the thermal resistance of this device may be neglected. The device may be associated with a localized thermal capacity Cf. The thermocouple is incorporated into the sensor during sensor fabrication and considered to lie within the sensor's median plane.

2. Contact between flow meter and plasterboard sample: The imperfection in contact between the heat flow meter and plasterboard is reflected by contact resistance Rc1.

3. First element of the assembly to be characterized: This element comprises the plasterboard sample. In the model, it was considered as a homogeneous material with thermal conductivity $\lambda_{\text {gyp }}$ and volumetric heat capacity $(\rho c)_{\text {gyp }}$; its thickness equals $1.25 \mathrm{~cm}$.

4. Contact between the two elements (plasterboard/PVC): The contact resistance is denoted $\mathrm{Rc}_{2}$. The thermocouple $\left(\mathrm{T}_{\mathrm{int}}\right)$ was inserted into an extremely thin groove cut into the PVC sample, which suggests that the temperature measurement is performed at the resistance $\mathrm{Rc}_{2}$ output.

5. Second element of the assembly to be characterized: This element comprises the PVC sample. Its thermal conductivity is denoted $\lambda_{\mathrm{PVC}}$ and volumetric heat capacity $(\rho \mathrm{c})_{\mathrm{PVC}}$; moreover, its thickness equals $1 \mathrm{~cm}$. Similarly, the thermocouple $\left(\mathrm{T}_{2}\right)$ was inserted into an extremely thin groove cut into the back face of the PVC sample.

\subsection{Inverse Method}

\subsubsection{Direct Model}

The various thermal properties are determined by means of an inversion based on a direct thermal conduction numerical model expressed in terms of finite differences. As described in the test protocol, temperatures measured both in the flow meter and on the back face of the PVC sample are set as the boundary conditions. The numerical model run in a Matlab ${ }^{\circledR}$ environment is obtained by discretizing the $1 \mathrm{D}$ heat equation to the second order according to an implicit formulation (Equation (1)). This procedure assumes that the second-order derivative of the heat equation is described by the following classical relation:

$$
\left.\frac{\partial^{2} T}{\partial x^{2}}\right|_{i, n+1}=\frac{T_{i-1}^{n+1}-2 T_{i}^{n+1}+T_{i+1}^{n+1}}{(\Delta x)^{2}}
$$

where $T(x, t)=T(i \Delta x, n \Delta t)=T_{i}^{n}$.

The initial temperature field is determined by considering that the state is stationary at the start of the test. Classically speaking, by way of steady-state regime relations, the linear temperature profiles in each material are calculated at $t=0$.

\subsubsection{Sensitivity Analysis}

In order to verify that the intended procedure is able to yield a simultaneous identification of the various target parameters, it is essential to conduct a sensitivity analysis. 
The objective of such an analysis is to determine whether the various thermal parameters to be identified have a significant effect on the responses to be optimized and whether the lack of correlation between these parameters still permits a simultaneous identification [31]. A sensitivity study also provides the forum for discussing the relevance of the load strategy and moreover may serve to optimize the strategy, which has not been carried out in our case. This study may lead to defining one or more optimal time intervals for the identification step.

A local sensitivity analysis is undertaken herein; it consists of setting nominal values for the seven parameters to be identified (Table 1) and then calculating the sensitivity coefficient for each parameter.

Table 1. Nominal values of the model parameters.

\begin{tabular}{cc}
\hline Parameters to Be Identified & Nominal Values \\
\hline $\mathrm{C}_{\mathrm{f}}$ & $900 \mathrm{~J} \mathrm{~K}^{-1} \mathrm{~m}^{-2}$ \\
\hline $\mathrm{R}_{\mathrm{c} 1, \mathrm{R}_{\mathrm{c} 2}}$ & $0.05 \mathrm{~K} \mathrm{~m}^{2} \mathrm{~W}^{-1}$ \\
\hline$\lambda_{\text {gyp }}$ & $0.33 \mathrm{~W} \mathrm{~m}^{-1} \mathrm{~K}^{-1}$ \\
\hline$(\rho)_{\text {gyp }}$ & $0.8310^{6} \mathrm{~J} \mathrm{~K}^{-1} \mathrm{~m}^{-3}$ \\
\hline$\lambda_{\mathrm{PVC}}$ & $0.2 \mathrm{~W} \mathrm{~m}^{-1} \mathrm{~K}^{-1}$ \\
\hline$(\rho \mathrm{c})_{\mathrm{PVC}}$ & $1.4510^{6} \mathrm{~J} \mathrm{~K}^{-1} \mathrm{~m}^{-3}$ \\
\hline
\end{tabular}

For both the plasterboard and PVC, the values listed in the manufacturer's documentation were used. The contact resistance values were set at high levels so as to be viewed in an unfavorable light. The flow meter capacity was set by considering a single copper layer composition, which happens to be the material with the highest capacitance.

The function of heat flow sensitivity to a parameter $p_{i}$ used in this study is defined as follows (2):

$$
Y_{p i}(t)=\frac{\Delta \phi_{p i}(t)}{\frac{\Delta p i}{p i}}
$$

where $\Delta \phi_{p i}(t)$ denotes the variation in heat flow density subsequent to a variation $\Delta p i$ in parameter $p_{i}$.

Figure 3 presents the curves plotting the functions of flow response sensitivity to the seven thermal parameters. The flow crossing the flow meter is also shown in order to facilitate understanding and discussion.

The first conclusion drawn from these curves is that all parameters exert a significant impact on the input flow. The presence of a sensor affects transfers by virtue of its thermal capacity and the sensor/plasterboard contact resistance. The two sensitivity curves $\mathrm{Y}_{\mathrm{Cf}}(\mathrm{t})$ and $Y_{R c 1}(t)$ are the ones with the smallest amplitudes, yet capacity $C_{\mathrm{f}}$ and contact resistance $R_{c 1}$ cannot be overlooked since they affect the rapidly variable regimes, in particular, the upward and downward jumps of pulses (e.g., Zone 2 in Figure 3). The values of these parameters may ultimately be set at the approximate nominal values in order to limit the number of parameters to be identified; however, this option was not selected herein in favor of the simultaneous identification of all seven parameters. Flow meter capacity, which remains constant from one test to the next, may also be identified ahead of time. Moreover, it can be considered that for other heating strategies with less sudden transitions, these parameters might be less influential and therefore neglected. 


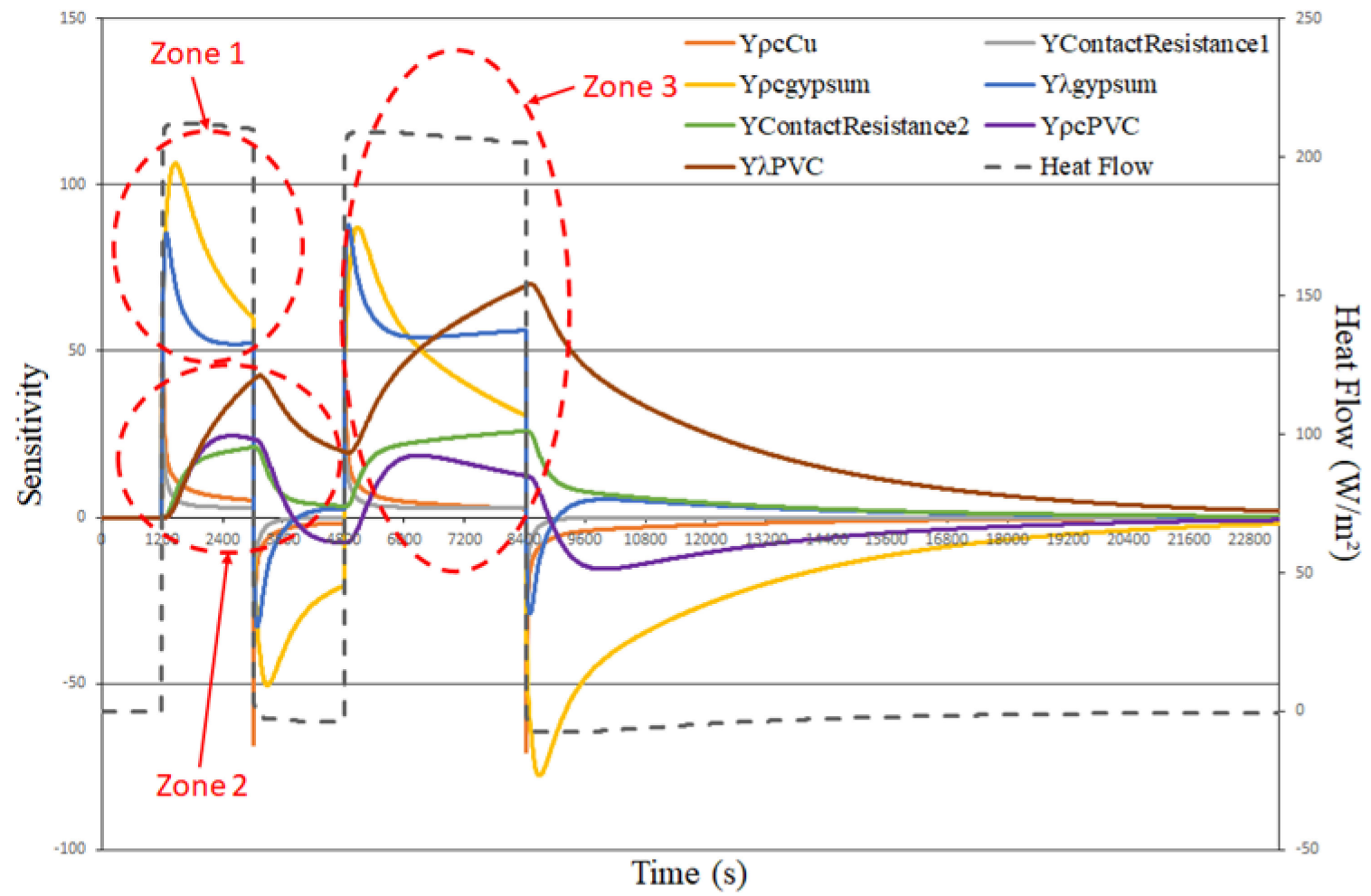

Figure 3. Sensitivity analysis of the flow response to the various thermal parameters.

The $Y_{\lambda \text { gyp }}(t)$ and $Y_{(\rho) \text { gyp }}(t)$ curves in Zone 1 highlight the strong sensitivity to the thermal properties of the plasterboard during the initial loading. Right from the outset, plasterboard behaves like a semi-infinite medium, and the sensitivities are observed to be proportional. As a case in point, the transfer in our case is solely established by the thermal effusivity of the first material. Subsequently, the two sensitivities become dissociated and are no longer proportional. It can even be observed that they intersect in Zone 3, once the pulse has been maintained over a longer time period. The graph indicates a possible identification of $\lambda_{\text {gyp }}$ and $(\rho c)_{\text {gyp }}$; the two curves are not proportional.

At the time when flow is affected by the plasterboard/PVC interface, input flow becomes increasingly sensitive to the PVC conductivity $\left(\lambda_{\mathrm{PVC}}\right)$ as well as to its volumetric heat capacity $\left((\rho \mathrm{c})_{\mathrm{PVC}}\right)$; the two curves are not proportional. A sign inversion can even be witnessed during the heating extinction phases. However, it can be observed that sensitivities to both PVC conductivity $\left(\mathrm{Y}_{\lambda P V C}(\mathrm{t})\right)$ and the second contact resistance $\mathrm{Y}_{\mathrm{Rc} 2}(\mathrm{t})$ have similar shapes and display a certain proportionality (Zone 3). This observation reveals the potential importance of the contact resistance and suggests a correlation between these parameters. Their simultaneous identification will therefore nonetheless prove to be difficult. Let us recall that the estimation of conductivity $\lambda_{\mathrm{PVC}}$ is one of the main objectives since it reflects the thermal insulation conductivity during the in situ applications planned on the walls.

To solve this problem, it was decided to provide additional information by taking into account the interface temperature between the two materials involved in the inversion process.

Figure 4 displays the sensitivity coefficient curves of the various model parameters in response to the interface temperature, as recorded between the plasterboard and PVC plate. These sensitivity coefficients will now be denoted Xpi(t) for each parameter pi. Sensitivity to the volumetric thermal capacity of the flow meter has not been shown since it is negligible relative to the other parameters. In focusing this analysis on the relation between sensitivity to $\mathrm{PVC}$ conductivity $\left(\mathrm{X}_{\lambda \mathrm{PVC}}\right)$ and sensitivity to the second contact resistance $X_{R c 2}(t)$, it can once again be stated that they both present proportional dynamics but this time with different signs. The proportionalities observed on the sensitivities of flow 
and interface temperature are thus quite distinct, making it possible to reject the premise of a correlation between them. Including the interface temperature in the optimization procedure makes it possible to envisage the simultaneous identification of all parameters.

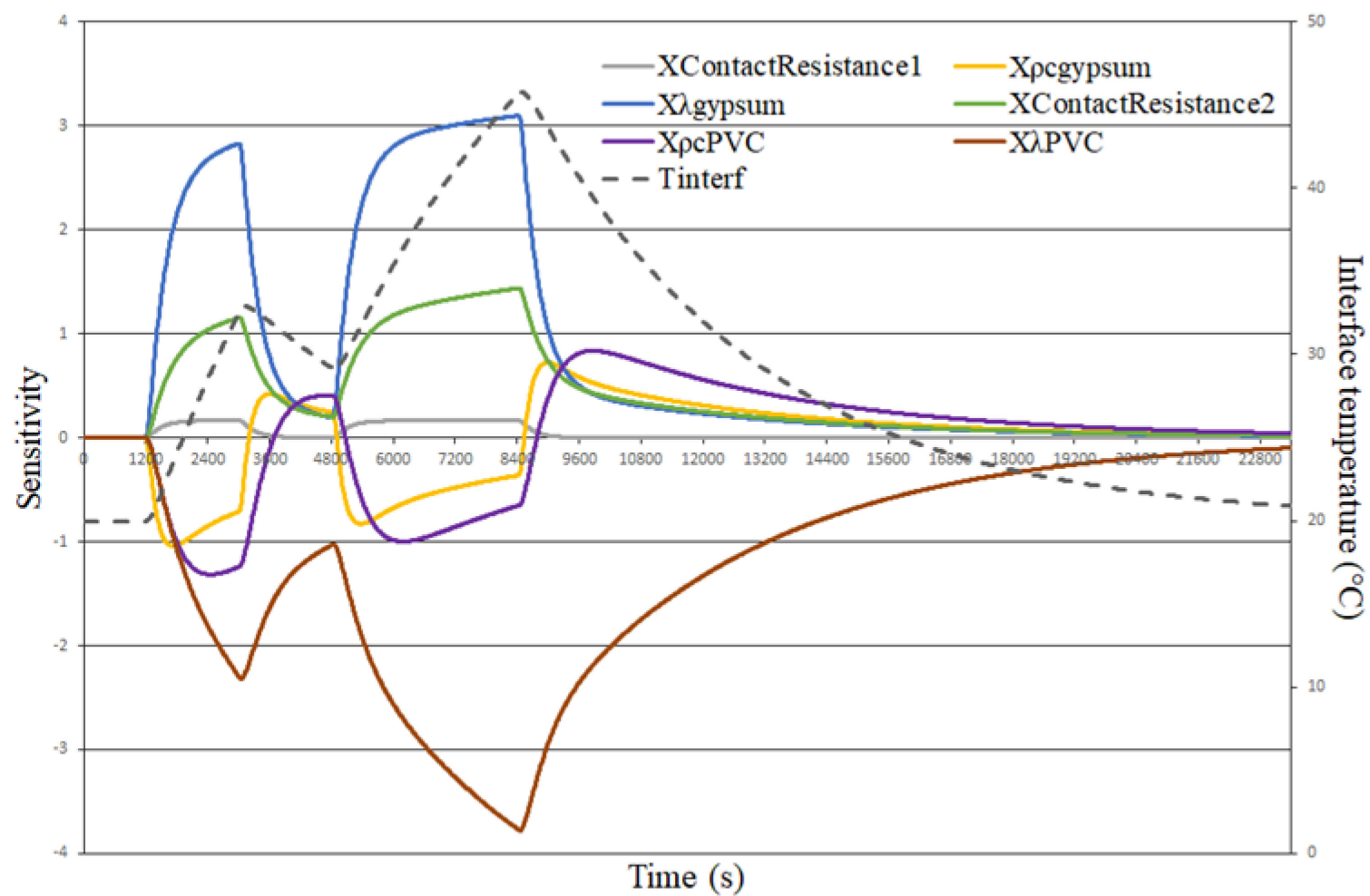

Figure 4. Sensitivity analysis of the interface temperature response to the various thermal parameters.

\subsubsection{Inversion Algorithm}

The parameters are estimated by applying Levenberg-Marquardt's optimization algorithm [32]; this method, widely used to solve nonlinear problems, is based on a minimization routine by iterating a cost function that depends on a combination of the tested parameters. In the typical case, such a cost function is built by calculating the quadratic error between an experimental curve and a simulated one.

In the special case of the method developed herein, the optimization procedure features a multi-objective purpose. More specifically, for each combination $p$ of parameters tested, the algorithm determines an initial cost function, denoted $E_{1}(p)$, by totaling the quadratic deviations between the measured and simulated input flow. It then calculates a second $E_{2}(p)$ value as the sum of quadratic deviations in the interface temperature between the two materials of both the measured and simulated assemblies. In this case, the algorithm will then seek to minimize a linear combination, denoted $F(p)$, of the two functions $E_{1}(p)$ and $E_{2}(p)$.

Based on the $n$ recordings at time step $\Delta t$, the cost functions $E_{1}(p)$ and $E_{2}(p)$ can be respectively described by the following Equation (3) and (4):

$$
\begin{gathered}
E_{1}(p)=\frac{\sum_{i=1}^{n}\left(\phi_{\text {sim }, p}(i)-\phi_{\exp }(i)\right)^{2}}{\sum_{i=1}^{n}\left(\phi_{\exp }(i)\right)^{2}} \\
E_{2}(p)=\frac{\sum_{i=1}^{n}\left(T_{\text {int }, \text { sim }, p}(i)-T_{\text {int }}(i)\right)^{2}}{\sum_{i=1}^{n}\left(T_{\text {int }}(i)-T_{\text {int }}(1)\right)^{2}}
\end{gathered}
$$

where $\phi_{\text {sim,p }}(i)$ and $T_{\text {int,sim,p }}(i)$ represent respectively the simulated surface flow density and temperature at the material interface with combination of parameters $p$; moreover, $\phi_{\exp }(i)$ 
denotes the experimental surface flow density, $T_{\text {int }}(i)$ the experimental temperature at the material interface, and $T_{\text {int }}(1)$ the initial interface temperature value.

The global error function $F(p)$ is thus defined by the relation (5) where $0 \leq \alpha \leq 1$.

$$
F(p)=\alpha * E_{1}(p)+(1-\alpha) * E_{2}(p)
$$

Independently of the normalization carried out on $E_{1}(p)$ and $E_{2}(p)$ in relations (3) and (4), the simulated heat flow density is obtained via numerical derivation of a temperature field. The noise stemming from the temperature measurement is numerically amplified, which in turn generates a much higher cost function $E_{1}(p)$ on the flow density values.

To define a value of coefficient $\alpha$, an initial optimization is performed with $\alpha=1$, which corresponds to a single-objective optimization on the input flow $\left(F(p)=E_{1}(p)+0 . E_{2}(p)\right)$. This phase leads to an initial determination of the cost functions $E_{1}\left(p_{\alpha=1}\right)$ and $E_{2}\left(p_{\alpha=1}\right)$, making it possible to deduce a value of $\alpha=E_{2}\left(p_{\alpha=1}\right) /\left(E_{1}\left(p_{\alpha=1}\right)+E_{2}\left(p_{\alpha=1}\right)\right.$, which then allows the two terms to be balanced in relation (5). At this point, the contributions of information stemming from both the flow density and interface temperature measurements are well balanced. With this value of $\alpha$, the multi-objective optimization can be conducted.

The inversion algorithm can thus be depicted by the following diagram (Figure 5).

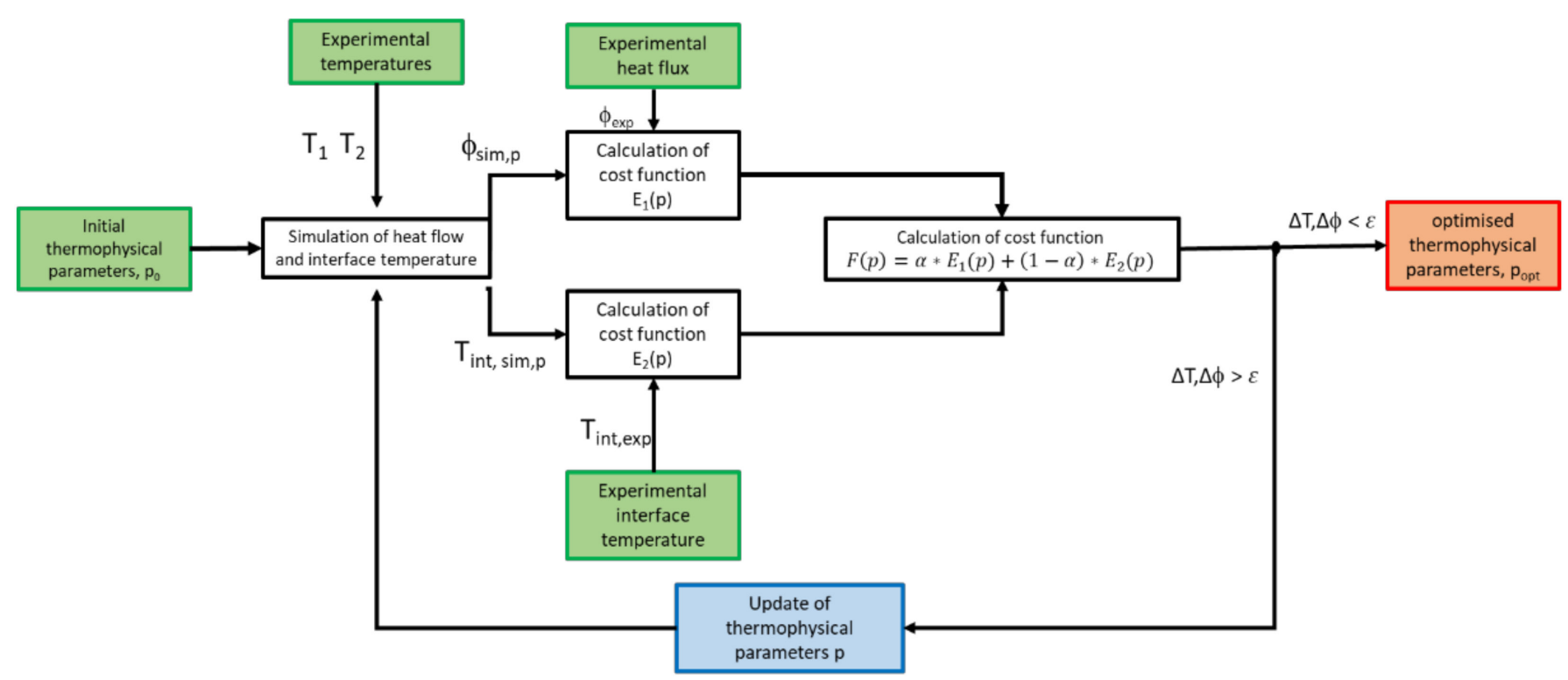

Figure 5. Schematic diagram of the inversion method.

\section{Results and Discussion}

\subsection{In-Laboratory Testing}

Testing was conducted in strict accordance with the protocol described above. Figures 6 and 7 show respectively the evolution in experimental and simulated heat flow, as well as the evolution in experimental and simulated temperatures. The calibration of simulated curves on the experimental curves was performed simultaneously, as per the procedure laid out in the previous part. In both cases, a very strong overlap could be noticed.

As regards this in-laboratory test, Figure 6 plainly reveals that flow density at the system input is zero until initiation of the 1st phase of heating. The hypothesis of a steadystate regime is thus verified. For this particular laboratory test, a thermal equilibrium status has actually been obtained, and moreover, temperatures are uniform across the various system elements. 


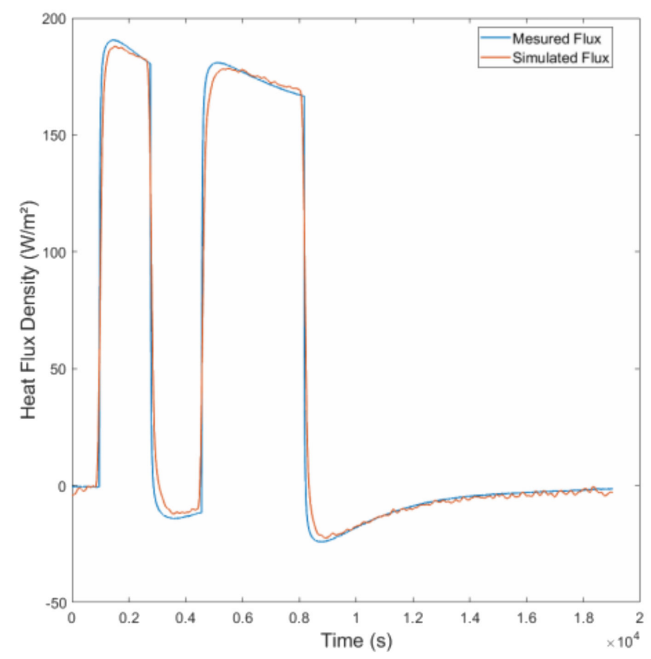

Figure 6. Evolution in both the simulated and experimental flow densities.

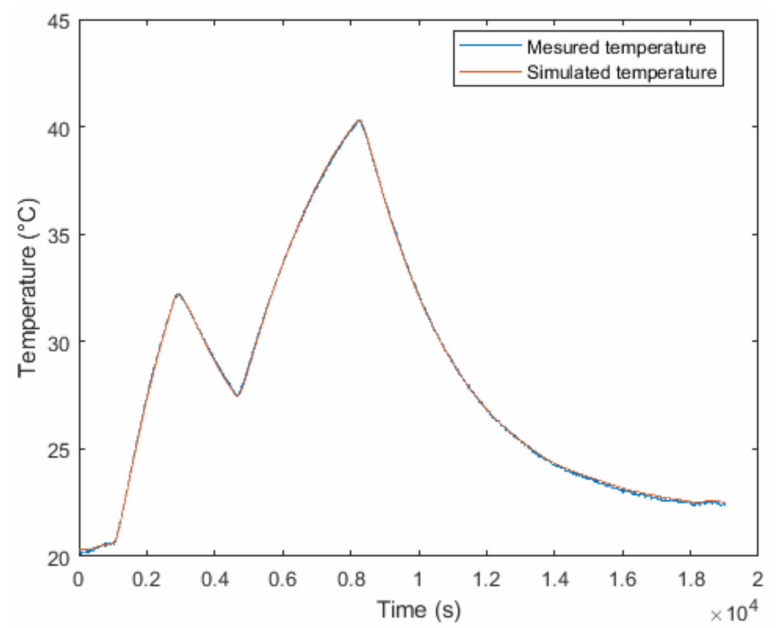

Figure 7. Evolution in both the simulated and experimental temperatures.

The values derived for the thermal characteristics of assembly materials during this identification procedure correspond to those determined previously, as summarized in Table 2.

Table 2. Reference values and results of the inversion procedure.

\begin{tabular}{ccc}
\hline Characteristics & Reference & Inversion Procedure \\
\hline Thickness plasterboard $(\mathrm{mm})$ & 13 & Known \\
$\lambda$ plasterboard $\left(\mathrm{W} \mathrm{m}^{-1} \mathrm{~K}^{-1}\right)$ & 0.33 & 0.284 \\
$\rho c$ plasterboard $\left(\mathrm{J} \mathrm{K}^{-1} \mathrm{~m}^{-3}\right)$ & $8.3 \times 10^{5}$ & $8.94 \times 10^{5}$ \\
\hline Thickness PVC $(\mathrm{mm})$ & 10 & Known \\
$\lambda$ PVC $\left(\mathrm{W} \mathrm{m}^{-1} \mathrm{~K}^{-1}\right)$ & 0.2 & 0.204 \\
$\rho$ c PVC $\left(\mathrm{J} \mathrm{K}^{-1} \mathrm{~m}^{-3}\right)$ & $1.45 \times 10^{6}$ & $1.12 \times 10^{6}$ \\
\hline
\end{tabular}

Parameter estimation also depends on a determination of the contact resistances and the hypothesis adopted regarding flow meter thermal characteristics. As exhibited by the analysis of sensitivity to the flow response, the flow meter thermal capacity does play a role, especially during the load modification phases. This sensitivity may explain the deviations visible in Figure 6 for these specific phases.

Confidence intervals may be calculated based on the input of Hessian knowledge. Other techniques exist, notably Monte Carlo simulation [33], which uses the standard 
root mean square error (RMSE) of the nonlinear model adjustment to observed data in order to produce "virtual" datasets, i.e., in the present case virtual input flow and interface temperature data. These data undergo optimization by means of the inversion algorithm, and a new group of parameters is obtained. Hence, the number of parameter groups coincides with the number of generations of virtual data. This series of optimizations serves to establish distributions for each estimated parameter and thus helps determine a standard deviation.

The number of optimizations is set at 100 in order to build a sufficiently representative data population. Janssen [34] actually found that beyond 100 tests, method efficiency did not improve.

From these 100 optimizations, it is possible to determine an average value of the thermal properties, along with the confidence interval (95\%). See Table 3 below for the corresponding values.

Table 3. Identified thermal properties.

\begin{tabular}{|c|c|c|c|}
\hline & Parameters & Average Values & Confidence Interval (95\%) \\
\hline Plasterboard & $\begin{array}{l}\lambda\left(\mathrm{W} \mathrm{m}^{-1} \mathrm{~K}^{-1}\right) \\
\rho c\left(\mathrm{~J} \mathrm{~K}^{-1} \mathrm{~m}^{-3}\right)\end{array}$ & $\begin{array}{c}0.285 \\
8.98 \times 10^{5}\end{array}$ & $\begin{array}{c}{[0.276 ; 0.293]} \\
{\left[8.69 \times 10^{5} ; 9.23 \times 10^{5}\right]}\end{array}$ \\
\hline $\begin{array}{c}\text { PVC } \\
\text { Trovidur }^{\circledR}\end{array}$ & $\begin{array}{l}\lambda\left(\mathrm{W} \mathrm{m}^{-1} \mathrm{~K}^{-1}\right) \\
\rho c\left(\mathrm{~J} \mathrm{~K}^{-1} \mathrm{~m}^{-3}\right)\end{array}$ & $\begin{array}{c}0.204 \\
1.11 \times 10^{6}\end{array}$ & $\begin{array}{c}{[0.198 ; 0.210]} \\
{\left[1.07 \times 10^{6} ; 1.140 \times 10^{6}\right]}\end{array}$ \\
\hline
\end{tabular}

For this test, the values of contact resistances Rc1 and Rc2 were estimated respectively at 0.049 and $0.037 \mathrm{~K} \mathrm{~m}^{2} \mathrm{~W}^{-1}$. These values are less than the nominal values selected for the sensitivity study.

\subsection{In Situ Application}

The wall under study is located in a brick building in northern France dating from the beginning of the 20th century. The building has undergone a major restoration effort; in particular, it has been insulated using bio-sourced materials. The wall (Figure 8) had initially been built in brick (a) $40 \mathrm{~cm}$ thick. It was insulated on the building's interior side with 30-cm thick hemp concrete blocks (b), which were then covered by a mud-straw coating mix (c) $1.2 \mathrm{~cm}$ thick. During the works phase, temperature sensors were installed in the aim of characterizing the hemp concrete once cast in place; subsequently, they served to track its thermal characteristics over time. A type $\mathrm{T}$ thermocouple was positioned at the interface between the coating and a hemp concrete block (temperature Ti), while another was inserted into the hemp concrete block $10 \mathrm{~cm}$ from its surface $\left(\mathrm{T}_{2}\right)$. Hence, the (mud-straw) coating assembly with a 10-cm thick slice of hemp concrete became the characterization target. Worksite-related constraints necessitated selecting this option of positioning the temperature sensor inside the hemp concrete block. The thermocouple wires were connected to a Graphtec ${ }^{\circledR}$ GL820 data logger device.

The need to locate sensors inside the wall itself obviously constitutes a disadvantage when applying the method. These sensors are very small in size; ideally, they must be planned during a construction or restoration phase, or else a minute opening would be required in the wall, which is not always desirable. The positioning of temperature sensors should be known with sufficient accuracy since the thicknesses of the two layers to be characterized are parameters considered to be known in the inversion procedure.

Figure 8 shows the part of the wall that needs to be characterized, as well as the device specifically introduced for this study. For the sake of clarity, the various elements have not been drawn to scale. 


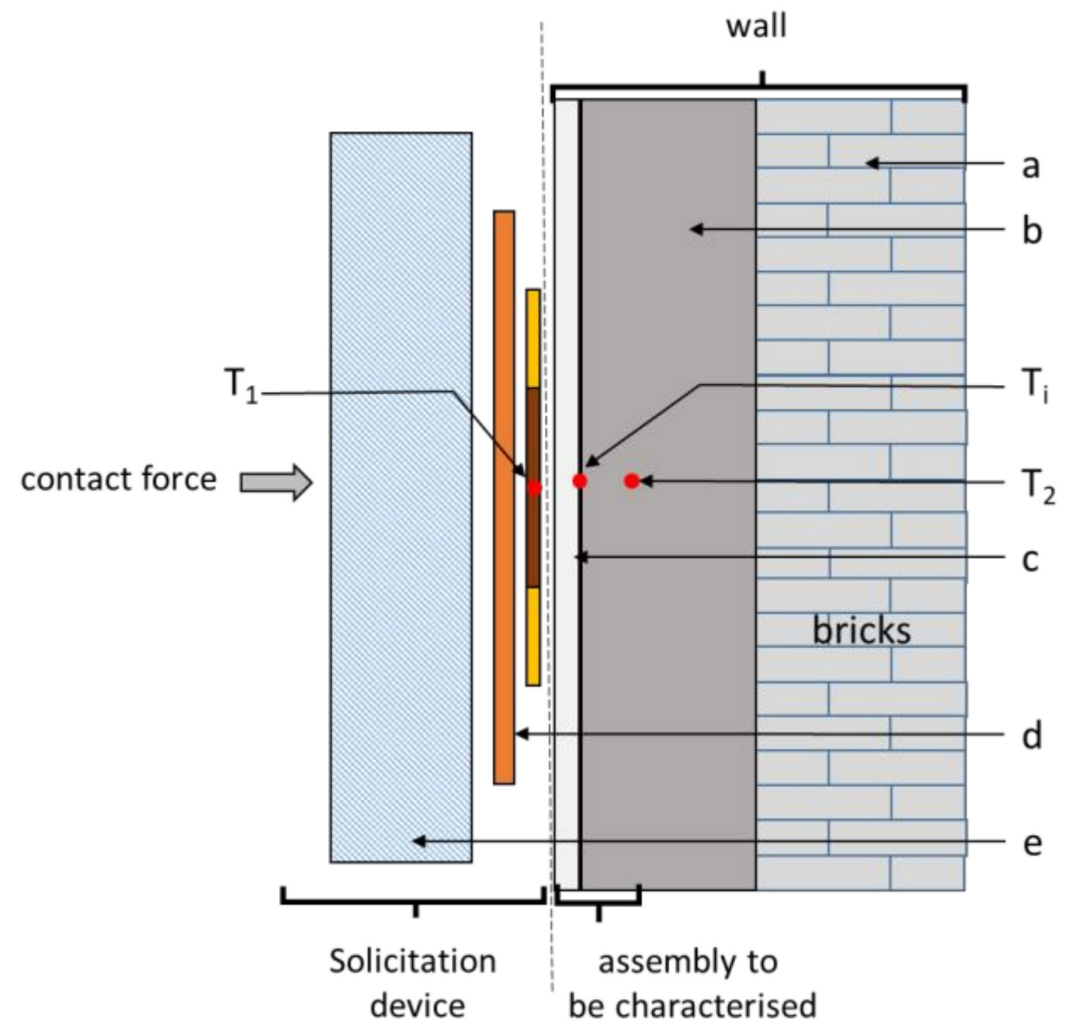

Figure 8. In situ experimental set-up.

The load was applied thanks to a large flat heating resistance (d) with a rectangular shape sized $0.9 \mathrm{~m} \times 1.1 \mathrm{~m}$. This KRL flexible heating model is of the Chromalox ${ }^{\circledR}$ brand; it was plated onto the wall by means of an $18-\mathrm{cm}$ thick polystyrene panel (e) with greater transverse dimensions. This panel directed the bulk of the power dissipated by the resistance toward the materials to be characterized. Preliminary observations of the surface temperature field on the flat resistance using infrared thermography revealed a very high degree of uniformity in the heat dissipation. This heavily loaded surface guarantees a unidirectional thermal conduction pattern in the central zone, where measurements were carried out. In order to measure the heat flow entering the wall, a $400-\mu \mathrm{m}$ thick tangential gradient flow meter $(0.15 \mathrm{~m} \times 0.15 \mathrm{~m})(\mathrm{c})$ was inserted between the resistance and the wall. This meter contained an integrated type $T$ thermocouple used to measure temperature $\left(T_{1}\right)$ at the system input. The device had to be implemented so as to ensure optimal contact conditions between the flow sensor and the wall (i.e., resistance $\mathrm{R}_{\mathrm{c} 1}$ ).

This characterization method is based on localized measurements, which represent exchanges should the loaded wall zone be considered a 1D system. In particular, the device is not to be placed on a zone affected by a thermal bridge.

The study was conducted over a two-day period in November 2019; the building was occupied at the time. On the first day, the experimental loading device $(c+d+e)$ was placed flat against the wall so as to minimize heat transfers. During this initial phase, the electrical resistance remained idle. The presence of this thermal resistance led to a reduction in heat transfer. Flow stabilization was monitored by means of the data acquisition system. This preliminary phase made it possible to minimize errors on the hypothesis of steady state adopted to determine the initial temperature field. On the second day, the test was performed with heating applied by the flat resistance.

In the case of the test, the data recording step took $31 \mathrm{~h}$. This duration was not optimized. This is a study perspective that would reduce the length of the stabilization time and shorten the recording time. The load consisted of dissipating $50 \mathrm{~W}$ of power within the $0.99 \mathrm{~m}^{2}$ of resistance in the form of a simple pulse lasting $5 \mathrm{~h}$, as shown in Figure 9. The choice of such a form of heating was once again dictated in this initial application by 
the search for simplicity in the experimental set-up. The flat resistance was connected to a continuous voltage source that was simply controlled by an operator. The reliance on other forms of signals constitutes one of the paths for future research stemming from this work. It is likely that other signals would enable the relative sensitivity of flow and temperature responses to the thermal characteristics of materials to be increased, thereby improving their ease of identification according to the inverse method. With this aim, various types of signals are currently under study (normal curves, square sine). It turns out that the pulse shape used herein leads to very abrupt transient temperature and flow regimes, which are highly sensitive to the first contact resistance. A smoother load shape would serve to limit this effect. In such a case, a controllable electrical power supply system would be necessary.

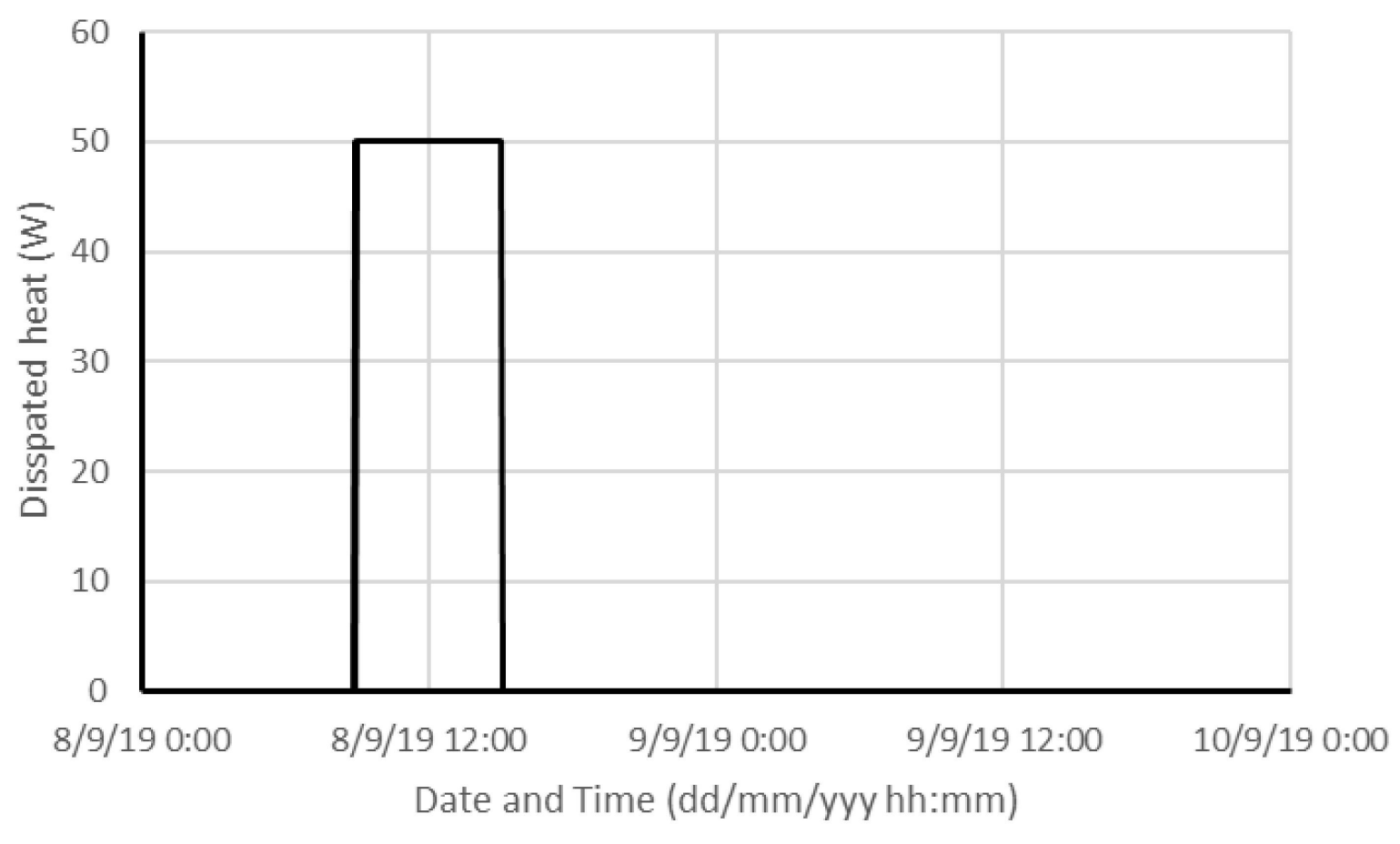

Figure 9. Heat dissipated in the flat resistance.

Figure 10 presents the evolution in temperatures both measured in situ and simulated after optimization using the inversion algorithm. The heat dissipated over $5 \mathrm{~h}$ by the resistance causes a temperature rise of approx. $22{ }^{\circ} \mathrm{C}$ (from $18{ }^{\circ} \mathrm{C}$ to $41^{\circ} \mathrm{C}$ ). Depending on the materials being tested, the injected power level may be increased, which would improve both the signal-to-noise ratio and inversion quality. Here lies another path for future research stemming from this work. Results show a strong overlap of the measured and simulated temperatures for the thermal property values listed in Table 4.

Using these same material thermal property values, the experimental flow density curve displays small deviations from the simulated curve, as depicted in Figure 11. 


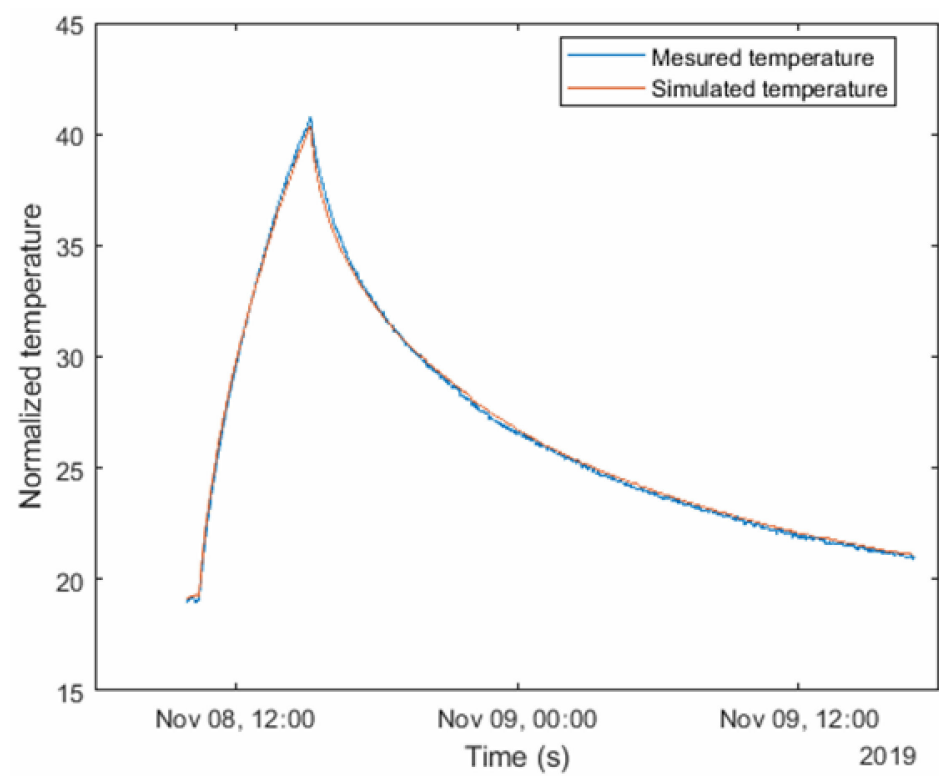

Figure 10. Temperatures both measured in situ and simulated.

Table 4. Thermal properties identified in situ.

\begin{tabular}{cccc}
\hline & Parameters & Identified Values & Confidence Interval (95\%) \\
\hline \multirow{2}{*}{ Mud-straw coating } & $\lambda\left(\mathrm{W} \mathrm{m}^{-1} \mathrm{~K}^{-1}\right)$ & 0.406 & {$[0.392 ; 0.421]$} \\
& $\rho \mathrm{c}\left(\mathrm{J} \mathrm{K}^{-1} \mathrm{~m}^{-3}\right)$ & $5.8 \times 10^{5}$ & {$\left[5.54 \times 10^{5} ; 6.07 \times 10^{5}\right]$} \\
\hline \multirow{2}{*}{ Hemp concrete block } & $\lambda\left(\mathrm{W} \mathrm{m}^{-1} \mathrm{~K}^{-1}\right)$ & 0.12 & {$[0.118 ; 0.125]$} \\
& $\rho \mathrm{c}\left(\mathrm{J} \mathrm{K}^{-1} \mathrm{~m}^{-3}\right)$ & $4.5 \times 10^{5}$ & {$\left[4.39 \times 10^{5} ; 4.62 \times 10^{5}\right]$} \\
\hline
\end{tabular}

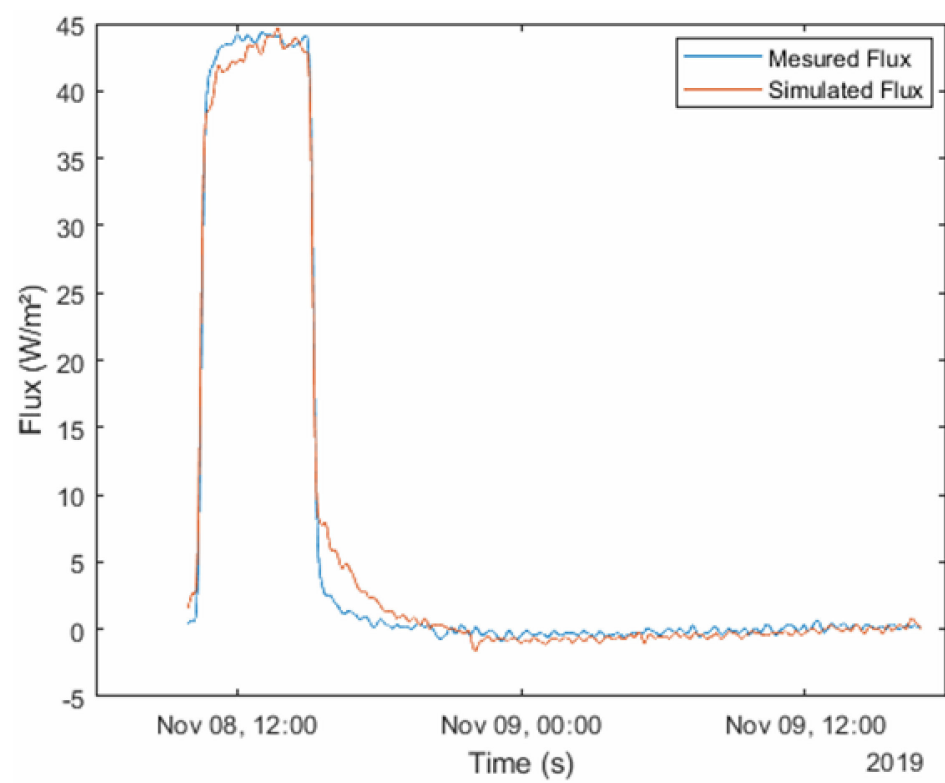

Figure 11. Flow densities both measured in situ and simulated.

The values obtained for the hemp concrete blocks correspond to those found in the literature. More specifically, Collet et al. [35] studied a wide range of hemp concrete compositions and recorded their thermal conductivities over the interval $[0.11 ; 0.17] \mathrm{W} \mathrm{m}^{-1} \mathrm{~K}^{-1}$. Walker and Pavia [36] examined commercial products and obtained values lying between 0.117 and $0.138 \mathrm{~W} \mathrm{~m}^{-1} \mathrm{~K}^{-1}$. 


\section{Conclusions}

An in situ method for estimating the thermal properties of materials composing a wall has been developed herein. This active method consists of imposing a flow on a wall and then recording the changes in input flow and input temperatures as well as temperatures at the interface of the tested materials. The loading device has been simply applied, and measurements could be conducted over periods on the order of a single day. The identification of thermal characteristics in the coating/insulating material double layer is made feasible thanks to a multi-objective inversion procedure that simultaneously adjusts flow density at the input and temperature at the two-material interface. This method was initially validated in the laboratory on materials encountered in building walls with known thermophysical properties. Afterwards, the method was implemented on an actual wall, and the characteristics of a mud-straw coating/hemp concrete assembly could be identified. A simple experimental device has been developed which does not require a complex control of the thermal solicitation. In our case, a simple pulse shaped flow was applied. The value of this method is the possibility to apply it independently of the indoor and outdoor weather conditions. One of the perspectives of this work could be the optimization of the control signal in order to improve the sensitivity of the responses to the conductivity of the insulation in the wall or to reduce the duration of the test. The method can only be used in cases of unidirectional heat transfer, ideally in an area away from wall heterogeneities, such as wall corners, thermal bridges, wooden frames, etc. Following the one-day in situ test, the estimated thermal conductivity of the insulation was found to be $0.12 \mathrm{~W} \mathrm{~m}^{-1} \mathrm{~K}^{-1}$ with a $95 \%$ confidence interval [0.118; 0.125$]$, in agreement with literature values.

Author Contributions: Conceptualization, D.D. and L.Z.; methodology, E.B., D.D. and L.Z.; software, E.B. and F.B.; validation, L.Z.; formal analysis, E.B. and D.D.; investigation, E.B., D.D. and F.B.; resources, F.B.; data curation, E.B.; writing-original draft preparation, E.B. and D.D.; writingreview \& editing, D.D., F.B. and L.Z.; visualization, D.D. and E.B.; supervision, D.D. and LZ.; project administration, D.D and L.Z.; funding acquisition, F.B. and D.D. All authors have read and agreed to the published version of the manuscript.

Funding: This research received no external funding.

Institutional Review Board Statement: Not applicable.

Informed Consent Statement: Not applicable.

Data Availability Statement: Not applicable.

Acknowledgments: The authors would like to thank the CD2E (an association set up to assist construction firms in their transition to renewable energy located in Loos-en-Gohelle, France) for making their center available to conduct in situ testing. All tests were performed as part of the Rehafutur project.

Conflicts of Interest: The authors declare no conflict of interest.

\section{References}

1. IEA Statistics and Data, International Energy Agency 2019. Available online: https://www.iea.org/statistics/ (accessed on 15 October 2019).

2. Johnston, D.; Miles-Shenton, D.; Farmer, D. Quantifying the domestic building fabric 'performance gap'. Build. Serv. Eng. Res. Technol. 2015, 36, 614-627. [CrossRef]

3. Menezes, A.C.; Cripps, A.; Bouchlaghem, D.; Buswell, R. Predicted vs. actual energy performance of non-domestic buildings: Using post-occupancy evaluation data to reduce the performance gap. Appl. Energy 2012, 97, 355-364. [CrossRef]

4. De Wilde, P. The gap between predicted and measured energy performance of buildings: A framework for investigation. Autom. Constr. 2014, 41, 40-49. [CrossRef]

5. Majcen, D.; Itard, L.; Visscher, H. Actual and theoretical gas consumption in Dutch dwellings: What causes the differences? Energy Policy 2013, 61, 460-471. [CrossRef]

6. Sunikka-Blank, M.; Galvin, R. Introducing the prebound effect: The gap between performance and actual energy consumption. Build. Res. Inf. 2012, 40, 260-273. [CrossRef] 
7. Schiavoni, S.; D'Alessandro, F.; Bianchi, F.; Asdrubali, F. Insulation materials for the building sector: A review and comparative analysis. Renew. Sustain. Energy Rev. 2016, 62, 988-1011. [CrossRef]

8. Pásztory, Z.; Anh Le, D.H. An overview of factors influencing thermal conductivity of building insulation materials. J. Build. Eng. 2021, 102604, 1-16. [CrossRef]

9. Derbal, R.; Lucas, A.; Brachelet, F.; Defer, D.; Antczak, E. Rehafutur-Insitu instrumentation for a comprehensive building analysis. Energy Procedia 2017, 139, 301-306. [CrossRef]

10. Thébault, S.; Bouchié, R. Refinement of the ISABELE method regarding uncertainty quantification and thermal dynamics modelling. Energy Build. 2018, 178, 182-205. [CrossRef]

11. Demeyer, S.; Le Sant, V.; Koenen, A.; Fischer, N.; Waeytens, J.; Bouchié, R. Bayesian uncertainty analysis of inversion models applied to the inference of thermal properties of walls. Energy Build. 2021, 249, 111188. [CrossRef]

12. Arregi, B.; Martinez, R.G.; Astudillo, J.; Ramos, J.C. Monitoring and thermal performance evaluation of two building envelope solutions in an apartment building. E3S Web Conf. 2020, 172, 25002. [CrossRef]

13. De Masi, R.F.; Ruggiero, S.; Vanoli, G.P. Multi-layered wall with vacuum insulation panels: Results of 5-years in-field monitoring and numerical analysis of aging effect on building consumptions. Appl. Energy 2020, 278, 115605. [CrossRef]

14. Yadav, M.; Agarwal, M. Biobased building materials for sustainable future: An overview. Mater. Today Proc. 2021, 43, 2895-2902. [CrossRef]

15. Colinart, T.; Pajeot, M.; Vinceslas, T.; De Menibus, A.; Lecompte, T. Thermal conductivity of biobased insulation building materials measured by hot disk: Possibilities and recommendation. J. Build. Eng. 2021, 43, 102858. [CrossRef]

16. Bendouma, M.; Colinart, T.; Glouannec, P.; Noël, H. Laboratory study on hygrothermal behavior of three external thermal insulation systems. Energy Build. 2020, 210, 109742. [CrossRef]

17. Colinart, T.; Lelievre, D.; Glouannec, P. Experimental and numerical analysis of the transient hygrothermal behavior of multilayered hemp concrete wall. Energy Build. 2016, 112, 1-11. [CrossRef]

18. Asli, M.; Brachelet, F.; Chauchois, A.; Antczak, E.; Defer, D. Numerical and experimental investigation of heat and mass transfer within bio-based material. Therm. Sci. 2019, 23, 23-31. [CrossRef]

19. Bienvenido-Huertas, D.; Moyano, J.; Marín, D.; Fresco-Contreras, R. Review of in situ methods for assessing the thermal transmittance of walls. Renew. Sustain. Energy Rev. 2018, 102, 356-371. [CrossRef]

20. Atsonios, I.A.; Mandilaras, I.D.; Kontogeorgos, D.A.; Founti, M.A. A comparative assessment of the standardized methods for the in-situ measurement of the thermal resistance of building walls. Energy Build. 2017, 154, 198-206. [CrossRef]

21. Rodler, A.; Guernouti, S.; Musy, M. Bayesian inference method for in situ thermal conductivity and heat capacity identification: Comparison to ISO standard. Constr. Build. Mater. 2018, 196, 574-593. [CrossRef]

22. Thermal Insulation-Building Elements-In Situ Measurement of Thermal Resistance and Thermal Transmittance-Part 1: Heat Flow Meter Method (ISO 9869-1:2014). Available online: https:/ / www.iso.org/standard/59697.html (accessed on 21 November 2021).

23. Teni, M.; Krstić, H.; Kosiński, P. Review and comparison of current experimental approaches for in-situ measurements of building walls thermal transmittance. Energy Build. 2019, 203, 109417. [CrossRef]

24. Asdrubali, F.; Baldinelli, G.; Bianchi, F. A quantitative methodology to evaluate thermal bridges in buildings. Appl. Energy 2012, 97, 365-373. [CrossRef]

25. Albatici, R.; Tonelli, A.M. Infrared thermovision technique for the assessment of thermal transmittance value of opaque building elements on site. Energy Build. 2010, 42, 2177-2183. [CrossRef]

26. Monchau, J.P.; Ibos, I.; Feuillet, V. Diagnosis of Insulated Building Walls Using Passive Infrared Thermography and Numerical Simulations. In Proceedings of the EWSHM-7th European Workshop on Structural Health Monitoring, Nantes, France, 8-11 July 2014; p. 10.

27. François, A.; Ibos, L.; Feuillet, V.; Meulemans, J. In situ measurement method for the quantification of the thermal transmittance of a non-homogeneous wall or a thermal bridge using an inverse technique and active infrared thermography. Energy Build. 2020, 233, 110633. [CrossRef]

28. Yang, Y.; Wu, T.V.; Sempey, A.; Dumoulin, J.; Batsale, J.-C. Short time non-destructive evaluation of thermal performances of building walls by studying transient heat transfer. Energy Build. 2018, 184, 141-151. [CrossRef]

29. Chaffar, K.; Chauchois, A.; Defer, D.; Zalewski, L. Thermal characterization of homogeneous walls using inverse method. Energy Build. 2014, 78, 248-255. [CrossRef]

30. Thureau, P. New thermal fluxmeters using particular auxiliary walls and zero-balanced methods of measurement. Sens. Actuators A Phys. 1993, 36, 57-63. [CrossRef]

31. Hamby, D.M. A review of techniques for parameter sensitivity analysis of environmental models. Environ. Monit. Assess. 1994, 32, 135-154. [CrossRef]

32. Levenberg, K. A method for the solution of certain non-linear problems in least squares. Q. Appl. Math. 1944, 2, 164-168. [CrossRef]

33. Robert, C.P.; Casella, G. Monte Carlo Statistical Methods, 2nd ed.; Springer: New York, NY, USA, 2004; p. 157.

34. Janssen, H. Monte-Carlo based uncertainty analysis: Sampling efficiency and sampling convergence. Reliab. Eng. Syst. Saf. 2013, 109, 123-132. [CrossRef] 
35. Collet, F.; Pretot, S. Experimental investigation of moisture buffering capacity of sprayed hemp concrete. Constr. Build. Mater. 2012, 36, 58-65. [CrossRef]

36. Walker, R.; Pavia, S. Thermal and moisture monitoring of an internally insulated historic brick wall. Build. Environ. 2018, 133, 178-186. [CrossRef] 